\title{
Ciência da Informação: uma utopia transdisciplinar?
}

\section{Information Science: a transdisciplinary utopia?}

\author{
Francisco José Daher Junior ${ }^{1}$, Jussara Borges ${ }^{2}$ \\ 1 Universidade Federal da Bahia, Salvador, Bahia, Brasil; Universidade Federal de Ouro Preto, Ouro Preto, Minas Gerais, Brasil. ORCID: \\ http://orcid.org/0000-0002-9214-4970
}

2 Universidade Federal da Bahia, Salvador, Bahia, Brasil; Universidade Federal do Rio Grande do Sul, Porto Alegre, Rio Grande do Sul, Brasil. ORCID: http://orcid.org/0000-0003-0157-8691

Autor para correspondência/Mail to: Francisco José Daher Junior, chicodaher51@gmail.com

Recebido/Submitted: 05 de fevereiro de 2021; Aceito/Approved: 17 de abril de 2021

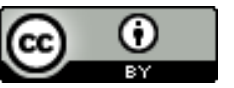

Copyright (c) 2021 Deher Junior \& Borges. Todo o conteúdo da Revista (incluindo-se instruções, política editorial e modelos) está sob uma licença Creative Commons Atribuição 4.0 Internacional. Ao serem publicados por esta Revista, os artigos são de livre uso em ambientes educacionais, de pesquisa e não comerciais, com atribuição de autoria obrigatória. Mais informações em http://revistas.ufpr.br/atoz/about/submissions\#copyrightNotice.

\begin{abstract}
Resumo
Introdução: busca responder a questões sobre a possibilidade de a Ciência da Informação (CI) se sustentar em um discurso epistêmico transdisciplinar. Método: discussão teórico-reflexiva amparada na dialógica, portanto, sem uma pretensão à síntese, na procura de respostas às questões suscitadas. Faz uma análise básica de três marcos da literatura que tratam do tema no âmbito da ciência em geral - Nicolescu, Pombo e Morin - de forma a trazê-los para o debate nos discursos da Cl. Resultados: a Cl traz, desde seus primeiros fundamentos históricos, a possibilidade de coexistir entre a lógica binária e a lógica inclusiva, sendo, portanto, capaz de transitar em seus Níveis de Realidade, a partir de tais possibilidades, dependendo do nível de complexidade em que estejam ocorrendo as investigações. Conclusão: a $\mathrm{Cl}$ revela a sua vocação transdisciplinar, por apresentar, em sua incompletude epistêmica, potenciais metodológicos de investigação capazes de sustentar estudos mais aprofundados sobre a dimensão humana, diante das transformações do mundo.
\end{abstract}

Palavras-chave: Ciência da Informação; Complexidade; Transdisciplinaridade.

\begin{abstract}
Introduction: it answers questions about the possibility of Information Science sustaining itself in a transdisciplinary epistemic discourse. Methods: it is a theoretical-reflective discussion supported by dialogic, therefore, without a claim to synthesis, in this research for answers to the questions raised. For this purpose, it makes a simple analysis of three milestones in the literature that deal with the subject in the scope of science in general - Nicolescu, Pombo and Morin - to bring them to the debate in the speeches of the IS. Results: IS brings, since its first historical foundations, the possibility of coexisting between binary logic and inclusive logic, being, therefore, able to move through its Levels of Reality, from such possibilities, depending on the level of complexity in which investigations are taking place. Conclusions: the IS reveals its transdisciplinary vocation, by presenting, in its epistemic incompleteness, potential research methods capable of sustaining further studies on the human dimension in the face of the transformations of the world.
\end{abstract}

Keywords: Information Science; Complexity; Transdisciplinarity.

\section{INTRODUÇÃO}

Somando-se à do título, mais duas perguntas inspiram a construção deste artigo. A mais óbvia é: questionar se a Ciência da Informação (CI) é transdisciplinar; e, outra, também não menos óbvia: como se pode admitir tal possibilidade diante dos desafios de se trazer o fenômeno à luz do conhecimento, sob um forte juízo cartesiano, que ainda define importantes rumos da própria Ciência? O presente trabalho, assim, tem por objetivo compor uma discussão teórico-reflexiva acerca do tema e, por se tratar de uma incursão inicial, nos balizamos na tríade proposta por Nicolescu (1999) - Complexidade, Níveis de Realidade e Lógica do Terceiro Incluído - como condição para a transdisciplinaridade.

Nosso mapa metodológico, sustentado pela dialógica, por não buscar eliminar as contradições entre conceitos e princípios (Morin, 1996), estrutura o artigo em três seções, com o objetivo de se identificar possíveis correlações entre os fundamentos de Nicolescu (1999) com a CI, conforme dissertado ao longo do trabalho. Na primeira, refletindo sobre a Teoria da Complexidade, sobretudo em Morin (1996, 2001, 2003, 2011), buscamos as aberturas para os temas subsequentes, por nos permitir uma visualização do contexto a partir de uma perspectiva polilógica presente na história da Ciência. A segunda parte, por sua vez, reflete sobre a disciplinaridade e seus desdobramentos (multi, inter e trans) na Ciência, dialogando com Pombo (2004), uma referência na área para, na última seção, buscar compreender a CI neste lugar, respondendo, assim, às questões que levantamos.

Bush (1945) e Borko (1968), precursores da CI na visão anglófona, trazem a discussão da complexidade e da interdisciplinaridade para o seu cerne, no âmbito de um discurso funcional-positivista. De forma assimétrica, chegamos a Silva (2016), que, ao se propor a fazer uma leitura do discurso de Borko (1968), acaba criando um contraponto para a questão da interdisciplinaridade, e, consequentemente, à proposta do artigo, que pretende transcendê-la. Dessa feita, buscamos, também de forma assimétrica, mesmo que tangencial, reforçar nossos argumentos com Saracevic (1996), Pinheiro (2013), Araújo (2009) e Marteleto e Saldanha (2016), em seus 
raciocínios sobre a interdisciplinaridade, a complexidade e a transdisciplinaridade, respectivamente, nos colocando de volta ao diálogo com Nicolescu (1999) para alcançarmos os objetivos do trabalho em curso. Assim, os critérios para seleção da bibliografia de base do artigo se assentam nos autores que consideramos mais representativos dos conceitos que fundamentam esta discussão. Esta subjetividade no critério de seleção dos autores-base representa a principal fragilidade metodológica do estudo. Contudo, é justamente tal consciência e registro que, de um lado, viabiliza o escopo de um estudo reduzido a um artigo e, de outro, denota seu rigor científico.

\section{A complexidade: caminhos e desafios}

Partimos da busca para entender e contextualizar a questão da complexidade como uma condição de se compreender a própria transdisciplinaridade. As primeiras discussões sobre a questão podem ser encontradas nas reflexões acerca da própria lógica - chegando à luz, especialmente, em função das contradições advindas da revolução científica que se deu no final do século XVII, a partir da associação entre ciência e técnica -, mas evidenciam-se nas ciências somente a partir dos séculos XIX e XX. Até então, a determinação do que viria a ser verdade, conforme Morin (2011), com a referida junção, se dava pelos princípios da ordem, da separação e da redutibilidade, validando, assim, a lógica clássica como dedutiva-indutiva-identitária, que se apresentava como capaz de eliminar as contradições do pensamento.

Sobre a lógica, porém, nunca é demais lembrar que pensadores, antes do Século XIX, como Vico (1979) ${ }^{1}$, Leibiniz $(1979)^{2}$ e Kant $(1979)^{3}$, entre outros, já se preocupavam com tal problema, questionando a binária, aristotélica, enquanto absoluta, que tanto fundamentou o pensamento cartesiano. Bachelard $(1978)^{4}$, no entanto, já no início do XX, questionando o princípio lógico de exclusão do erro, contido no pensamento de Descartes, começava, de fato, a sistematizar o pensamento para a complexidade. Bachelard, aliás, segundo Morin (1996), foi quem trouxe de forma mais efetiva o tema complexidade como necessário à investigação científica, a partir de suas reflexões acerca da negação da existência de qualquer fenômeno simples. O próprio Bachelard (1978), sustentando-se em Dupréel, acreditava que isso ocorreria pelo fato de a ideia do simples fazer parte de um processo complexo, assim como da própria experiência que revela tal ideia, que, para ele, nunca seria simples.

O século XX, de acordo com Morin (1996), citando Weaver (1948), seria o da complexidade, uma vez que o XIX representaria a complexidade desorganizada. Acreditamos, porém, que a complexidade, numa visão que a interpreta como um caminho para reforma do pensamento e alargamento do conhecimento, continua com um prognóstico ainda incerto no século XXI. Isso devido ao vigor do pensamento funcional-positivista, que tanto influencia na concepção conceitual das novas mídias.

Tal influência faz-se presente nos processos de comunicação não-humana, para além do suporte, concebidos a partir do princípio behaviorista de estímulo e resposta - fundamentados na Matemática, por meio do desenvolvimento dos algoritmos, na Psicologia e na Engenharia Comportamental, entre outras áreas - que impactam no aperfeiçoamento das chamadas redes neurais artificiais. Importante ressaltar, porém, conforme veremos mais adiante, que as escolas funcional-positivistas também tiveram forte influência no pensamento complexo sistêmico nas áreas das engenharias, administração, computação e da própria CI, entre outras.

Os impactos, sobretudo aqueles advindos das revoluções tecnológicas, por um lado, podem representar um avanço profundo na evolução do conhecimento e das ciências, mas, por outro lado, recorrendo a Morin (2011), podem propiciar uma perspectiva neototalitária, a partir de uma possibilidade de declínio da democracia (referência que o autor faz ao analisar as redes neurais). Por isso, se faz importante destacar que o assombro neototalitário está vindo à tona com o crescimento de movimentos conservadores de extrema-direita, principalmente desde 2016, a partir do resultado de eleições em vários pontos do mundo. Mais recentemente, tal fenômeno se faz presente na crise gerada pela pandemia do novo Coronavírus ${ }^{5}$, que, além de revelar o negacionismo da Ciência, tem colocado em xeque modelos econômicos, políticos e ambientais, principalmente, no que diz respeito a uma possível quebra da então tendência de longo prazo relativa à globalização, que ora se apresenta.

Com isso, corroboramos com o pensamento de Morin (2011, p. 5) em sua análise sobre as possíveis dicotomias geradas pelo desenvolvimento das redes neurais artificiais. Sobre a questão, ele afirma que somente o pensamento complexo poderia opor-se à tendência neototalitária devido à sua capacidade de "[...] desenvolver a autonomia pensante e a reflexão consciente do indivíduo", provocando a reforma do próprio pensamento.

Morin (2011) aponta alguns caminhos para se entender a complexidade. O primeiro deles, "a irredutibilidade do acaso e da desordem", que permite a incerteza da própria incerteza gerada pelo acaso; o segundo, a transgressão nas ciências naturais "[...] dos limites daquilo que podemos chamar de abstração universalista que elimina a

\footnotetext{
${ }^{1}$ Original publicado em 1725.

${ }^{2}$ Original publicado em 1714 .

${ }^{3}$ Original publicado em 1781 .

${ }^{4}$ Original publicado em 1932.

${ }^{5} \mathrm{O}$ novo Coronavírus, causador da doença Convid-19, foi identificado na China em dezembro de 2019, se espalhando rapidamente para o todo o mundo, levando a Organização Mundial de Saúde (OMS) a classificá-la, no dia 11/02/2020, como pandemia. Até o fechamento deste artigo, no dia 05/02/2021, segundo dados do Johns Hopkins Coronavirus Resource Center (CRC), o mundo tinha 105.097.000 casos, com o registro de 2.289.979 mortes.
} 
singularidade"; o terceiro, a complicação, "[...] a partir do momento em que percebemos que os fenômenos biológicos e sociais apresentavam um número incalculável de inter-reações, de inter-retroações"; o quarto, o princípio da ordem e da desordem, se opondo, citando Foster $(1959)^{6}$, ao princípio clássico de uma ordem natural obedecendo a leis naturais; o quinto, a própria organização, para ser pensada, simultaneamente, como "[...] unidade e multiplicação", o sexto, o princípio hologramático, a partir do exemplo de que uma simples célula contém informações de uma genética global; e, finalmente, o sétimo, ao colocar a necessidade de o observador voltar sempre à sua própria observação

Em seu cerne mais teórico, por tais caminhos, segundo Morin (1996), podemos evitar dois erros básicos quando nos propomos pensar a complexidade. O primeiro é não confundir complexidade como uma receita para todos os problemas do pensamento, mas, ao contrário, como uma motivação dinâmica capaz de alargar o próprio pensamento em busca do conhecimento. O segundo erro, por sua vez, é dar um sinônimo de completude à complexidade. Isso porque, de acordo com Morin (1996, p. 176), ao contrário, o seu problema estaria na "[...] incompletude do conhecimento", como meio de se "[...] dar conta daquilo que os tipos de pensamento mutilante se desfaz", lutando não contra a "[...] incompletude, mas contra a mutilação".

Sabemos, no entanto, que o debate ainda se inicia em nível da Ciência, contexto que nos transporta para a discussão posterior, que objetiva investigar os aspectos mais circunscritos à CI.

\section{Multi, inter e trans: um debate que ainda se inicia}

Comecemos com a afirmativa de que a CI, historicamente, sempre buscou novas fronteiras do conhecimento, e que, por nossa interpretação, deve se preocupar em compreender os aparentes espaços vazios que ali se encontram. Com tal postura é que buscaremos sustentar o caráter transdisciplinar da CI, ainda que em nível hipotético, devido à sua característica principal de não estar fixamente em lugar algum, abrindo, assim, campos para novos conhecimentos.

Pombo (2004) faz importante reflexão sobre os temas que compõem o título desta parte do artigo, já, de imediato, se colocando favorável à interdisciplinaridade como a melhor opção para se superar o estágio disciplinar. Isso, porque, segundo ela, a interdisciplinaridade apresenta possibilidade de propiciar a convergência e a complementaridade. A partir dos prefixos que compõem os temas em questão, Pombo (2004) classifica pluri e multi como uma só coisa, designando um estado de coordenação, e inter e trans, respectivamente, de combinação e fusão. Ela vê os dois primeiros atributos numa perspectiva paralelista: a interdisciplinaridade como convergência e a transdisciplinaridade como uma "[...] aspiração à homogeneização [...] enquanto passagem a um estágio superior" (Pombo, 2004, p. 14-15), caso os fenômenos sejam pensados em uma ordem crescente.

Pombo (2004), quando relaciona tais estados com a complexidade, aponta a interdisciplinaridade como a condição para se atingi-la, sustentando-se em três fundamentos: 1) na fecundação recíproca das disciplinas, por meio da transferência de conceitos; 2) na aproximação disciplinar criando possibilidades de maior aprofundamento no próprio conhecimento e, 3) na construção de novos objetos do conhecimento.

A autora relata também sobre a abundância das teorias acerca da interdisciplinaridade, mas pleiteia um discurso unificado que melhor lhe fundamente. Na citada trajetória, Pombo (2004, p. 32) chega à conclusão de que é preciso alargarmos o conceito, a partir do alargamento da própria Ciência, que, cada vez mais transversal, precisa estar "[...] atenta às novas complexidades que constantemente descobre e inventa", superando, assim, o paradigma cartesiano de divisão do conhecimento.

A análise de Pombo (2004), esclarecedora e didática para entendermos a questão, no entanto, nos chama a atenção ao suposto caráter homogeneizante da transdisciplinaridade, apesar de a autora não avançar nesta crítica ao longo do texto por nós estudado. Estaria a transdisciplinaridade propensa a uma degradação, uma vez que as condições homogeneizantes tendem a nos levar para tal lugar? Ou, ainda, se essa condição estaria na concepção de algumas características da transdisciplinaridade que dizem respeito a sua busca por uma unidade de método e critérios explicativos comuns? E, finalmente, se tal condição visaria uma formalização metodológica, como sugere Nicolescu (1999), colocando-a em um estágio que está entre, através e além das disciplinas?

A necessidade dessa formalização - observemos que a própria Pombo (2004) cobrou tal condição para a interdisciplinaridade - se faz necessária pois, de acordo com Nicolescu (1999), a transdisciplinaridade, sem isso, seria uma proposta vazia, acrescentando que a base para a metodologia estaria na conjunção entre os postulados "Níveis de Realidade, da Complexidade e da Lógica do Terceiro Incluído" (Nicolescu, 1999, p. 12). Ao contrário de Pombo (2004), que vê na interdisciplinaridade o caminho para a complexidade, para a nossa reflexão, no entanto, o paradigma se apresenta como uma condição constitutiva da metodologia transdisciplinar, conforme argumentamos mais adiante.

\footnotetext{
${ }^{6} \mathrm{O}$ físico, matemático e biólogo austríaco Heinz Von Foster foi um dos fundadores da Cibernética, que buscou uma aproximação entre as teorias da Comunicação com a Teoria dos Sistemas. Ele defendia que a realidade era formada a partir de uma observação, denominada como de segunda ordem, a partir do primeiro ato de observar, pois, uma vez que toda realidade só se formaria por meio de processos cognitivos de construção do observador. Isso deu origem ao conceito de Cibernética de segunda ordem, como um sistema capaz de explicar a auto-organização que se estabelecem nos sistemas comunicação (Cunha, 2009).
} 


\section{Ciência da Informação: a complexidade no âmago transdisciplinar}

Os fundamentos que constituem a CI podem ser encontrados na Antiguidade - na visão enciclopedista de Aristóteles e no universalismo preconizado por Platão -, cujas bases se fortalecem no século XVII, quando a ciência se aproxima da técnica. Posteriormente, especialmente em Kant (século XVIII), com a chegada do Iluminismo, a perspectiva da universalização do conhecimento, a partir de uma teorização mais robusta, ganha corpo, materializando-se, no Século XIX, na Enciclopédia, assim como, na mesma época, na consolidação da Arquivologia, da Biblioteconomia e da Museologia enquanto disciplinas. Constitui-se, portanto, na Europa, a Ciência da Documentação, e, a partir de uma visão positivista-funcionalista, com Vannevar Bush, no século XX, dá-se a sua denominação enquanto Ciência da Informação, com suas primeiras fundamentações, conforme Barreto (2007), sendo apresentadas na Royal Society Scientific Information Conference, realizada em 1948, em Londres.

Fazendo um recorte da visão anglófona da CI que se constitui a partir do século XX, podemos afirmar que a questão da interdisciplinaridade sempre esteve presente na sua pauta epistemológica. Borko (1968, p. 3), via a interdisciplinaridade num viés funcional-positivista. Tal interdisciplinaridade estaria associada "[...] a campos como matemática, lógica, linguística, psicologia, informática, pesquisa de operações, artes gráficas, comunicações, ciência da biblioteca, gestão, e outros campos similares", ocupando um lugar nas ciências pura e aplicada. Aqui podemos localizar os fundamentos preconizados por Pombo (2004) relativos à busca pela superação de um estágio disciplinar, em uma perspectiva de convergência e complementação.

Silva (2016, p. 36), no entanto, ao fazer uma análise do discurso de Borko (1968), entendeu a interdisciplinaridade preconizada por ele enquanto uma instância temporal e certa "[...] categoria de ação", citando Fazenda (1994). Apesar de ressaltar as reflexões de Borko (1968) como importantes para a construção da CI, ele considera contraproducente o seu discurso acerca da interdisciplinaridade, com capacidade, inclusive, de promover o enfraquecimento da CI. Segundo Silva (2016), isso porque permitiria a importação de conceitos de outras áreas em um lugar que ainda necessita fortalecer o seu próprio estatuto. Pombo (2004, p. 22), quando aborda a heurística no âmbito da ciência, ao contrário de Silva (2016), vê esta possibilidade como um processo de fecundação recíproca das disciplinas, que ocorre por meio da transferência de conceitos, da discussão de problemas éticos e de métodos "[..] com vistas a uma leitura mais rica da realidade".

As distintas percepções advindas dos discursos de Silva (2016) e Pombo (2004) nos conduzem a afirmar que, desde Bush (1945), e ficando mais explícita em Borko (1968), mesmo sem consenso, a interdisciplinaridade permanece na tônica das discussões da CI. Trazemos Saracevic (1996) para referendar essa afirmativa, que, ao aliar a problemática da CI aos impactos das transformações tecnológicas a vê como uma possibilidade de estudar melhor a relação homem e natureza, aspecto ainda não resolvido em suas dimensões teóricas e práticas, sustentando que, para tal, faz-se necessário se implementar uma mudança paradigmática em seu campo, ou seja, ao nosso ver, entendê-la interdisciplinar.

Aliamos tais argumentos às concepções de Pinheiro (2013), que também vê a CI interdisciplinar, em uma concepção mais próxima aos desafios contemporâneo de uma busca ampliada do conhecimento. Interpretamos que ela sustenta a proposição ao considerar o que denomina de caráter mutante da CI, que assumiu frentes em vários campos do conhecimento - política, educação, sociedade e cultura -, como capaz de nos instigar a estudar as fronteiras epistêmicas atingidas por ela.

Retomando os argumentos de Silva (2016) quanto ao discurso de Borko (1968), consideramos que, apesar de consistentes, quando correlacionados com as posições de Saracevic (1996) e Pinheiro (2013), porém, revelam uma preocupação de excessiva defesa de um campo que não se comporta mais em si mesmo, devido a sua própria complexidade. Complexidade tal que vem sendo reconhecida desde as fundamentações de Bush (1945), independentemente do discurso epistêmico que se apresente. No nosso entendimento, por carregar a complexidade, a interdisciplinaridade já se impõe à revelia de tais discursos, e, mais, apresenta um dos pilares da transdisciplinaridade, o que pode apontar o caminho para onde a CI se projeta.

Atendo-nos um pouco mais para a questão da complexidade, recorremos a Araújo (2009) na direção da problematização levantada acerca da transdisciplinaridade. Ao analisar as diversas correntes teóricas da CI, desde as positivistas da década de 1960 até os caminhos das ciências hermenêuticas em Cornelius (1996) e Capurro (2003), Araújo (2009) conclui que a superação teórica da CI está na complexidade. Ele argumenta, porém, que as fundamentações positivistas continuam presentes nos estudos da atualidade. A perpetuação positivista, também analisada por Marteleto e Saldanha (2016), se dá pela capacidade de renovação das escolas francófonas e anglófonas ao longo do tempo. Os mesmos autores, no entanto, apesar de reconhecerem tal vigor nos discursos acerca da informação e da comunicação, admitem a complexidade que envolve a área e, assim, vislumbram também a transdisciplinaridade como uma possibilidade epistemológica para a CI.

Façamos agora um exercício para buscar reconhecer elementos da complexidade no próprio discurso de Bush (1945), construído sob uma identidade funcional-positivista. Para tanto, vamos considerar aqui parte da análise de Santos (2003, p. 3) ao artigo "As we may think" (Bush, 1945), segundo a qual a visão teórica e prática acerca da informação projetam utopias interdisciplinares, como a "[...] de romper com as comportas que aprisionam 
a abordagem do problema da informação no limite estreito das disciplinas", e também na projeção complexa apoiada "[...] nas esperanças geradas pelo surgimento da tecnologia informática e sua capacidade de processar um volume cada vez maior de informação e que se materializou mais tarde na internet".

Para a reflexão, se faz necessário também colocar que a CI nascia em ambiente que projetava as primeiras teorias da complexidade que estavam por vir durante e depois do final da Segunda Guerra Mundial, em cujas visões foram alargadas, como vimos anteriormente, por Morin (1996, 2003, 2011), em busca de uma superação dos discursos funcionalistas, racionalistas e relativistas, influenciado, talvez, por Bachelard (1978) - ele próprio considerado como relativista -, que clamava por mudanças nas ciências em função do novo conceito de causalidade que se constituía sob efeitos da descoberta do quantum: projetado a partir da mecânica quântica.

A complexidade, como citado por Morin (1996), foi uma das preocupações de Weaver (1948), a quem alguns autores atribuem como um dos pioneiros a discutir sistematicamente o tema, buscando interpretá-la na relação desordem-ordem. Tais conceitos, em parte, foram apropriados pelo mesmo Morin (1996), em definições sobre os caminhos da complexidade, conforme vimos anteriormente.

Se observarmos cuidadosamente o pensamento, o ambiente e a época em que a complexidade começava a ser pensada sistematicamente, percebemos que os problemas levantados por Weaver (1948), estavam presentes nas preocupações e projeções de Bush (1945), para a questão da informação e de suas possibilidades de suporte. Os desafios da CI lançados por Bush (1945) para o futuro, como vimos na análise de Santos (2003), correspondem ao que Weaver (1948) projetava, de acordo com nossa interpretação, para as ciências, por possibilitar o desenvolvimento de dispositivos eletrônicos capazes de processar cálculos complexos, e a interdisciplinaridade, que podemos traduzir na sua denominação do que vinha a ser "equipe mista" como aquela capaz de resolver problemas oriundos da complexidade organizada.

Admitindo a complexidade na CI, e que tal complexidade tende a transcender as bases teóricas funcionaispositivistas, racionalistas e até mesmo relativistas para a possibilidade de uma reunificação transdisciplinar aqui citamos Bolshaw (2015), por concordar com a interpretação de que Morin atribui ao relativismo cultural, juntamente com a valorização disciplinar, a capacidade de retirada de nossa visão de conjunto sobre o mundo precisamos avançar para responder às perguntas iniciais deste artigo. Destarte, recorremos à Nicolescu (1999), para tentar, a partir de sua visão, perceber se a CI, além da complexidade, comporta outros níveis de realidade e admite, igualmente, a transcendência da lógica binária para, então, poder ser pensada como transdisciplinar.

Nicolescu (1999, p. 12), numa visão mais radical, coloca que somente a Física comportaria, de forma completa, os postulados da complexidade, dos níveis de realidade e a lógica do terceiro incluído, e que as demais disciplinas, por falta de uma formalização matemática rigorosa em suas bases, teriam um grau de transdisciplinaridade mais ou menos próximo da multidisciplinaridade, da interdisciplinaridade ou somente da disciplinaridade, sendo todas, porém, simbolicamente, "[...] as quatro flechas de um único e mesmo arco: o do conhecimento" (Nicolescu, 1999, p. 13).

Vejamos inicialmente, à luz de nossos objetivos, o que vem a ser Nível de Realidade. Na Física, tal postulado, segundo Nicolescu, estaria representado por:

[...] um conjunto de sistemas invariável sob a ação de um número de leis gerais: por exemplo, as entidades quânticas submetidas às leis quânticas, as quais estão radicalmente separadas das leis do mundo macrofísico. Isto quer dizer que dois níveis de Realidade são diferentes se, passando de um ao outro, houver ruptura das leis e ruptura dos conceitos fundamentais (como, por exemplo, a causalidade) (Nicolescu, 1999, p. 18).

No citado processo, as entidades quânticas, por mais separadas que possam estar, mantêm uma interação entre si, criando, ao contrário do mundo macrofísico, uma outra causalidade, conforme Nicolescu (1999). Assim, os níveis de realidade se mostram de forma diferente quando comparados, por exemplo, nas abordagens sistêmicas, ao que chamamos de níveis de organização.

De forma menos radical, Nicolescu (1999, p. 15) busca trazer o exemplo do mundo quântico para o cotidiano, mostrando que a questão não se apresenta de forma a surpreender. Segundo ele, isso, porque, na relação entre as pessoas, se estabelece "[...] um misterioso fator de interação, não redutível às propriedades dos diferentes indivíduos". O processo, critica o autor, é sempre repelido para o campo da subjetividade, dando-se um conceito dogmático de realidade que se estabelece em um único nível.

A chamada revolução quântica, segundo Nicolescu (1999), por sua vez, é capaz de colocar tal dogma em xeque, por causar um impacto cultural. A realidade, assim, passaria a ser definida como, "[...] em primeiro lugar, aquilo que resiste a nossas experiências, representações, descrições, imagens ou formalizações matemáticas", afirma Nicolescu (1999, p. 15), que atribui à física quântica a possibilidade de nos fazer perceber "[...] que a abstração não é um simples intermediário entre nós e a Natureza, uma ferramenta para descrever a realidade, mas uma das partes constitutivas da Natureza" (Nicolescu, 1999, p. 17).

A realidade, portanto, teria a capacidade de transcender a própria construção social, apresentando-se, por 
conseguinte, trans-subjetiva. Nesta outra relação, a noção cartesiana que a coloca numa instância unidimensional, cede lugar ao que Nicolescu (1999) define como realidade multidimensional, impactando diretamente na reforma do pensamento científico, pois altera a concepção do que vem a ser sujeito e objeto.

O resultado dessa relação, segundo Nicolescu (1999, p. 30), é impactante no método transdisciplinar, uma vez que a "[...] implexidade é uma complexidade implicante ou uma implicação complexa na qual objeto e sujeito, observado e observador estão ligados". Dessa maneira, um dos desafios do método é conseguir: "[...] desdobrar essa implexidade sem rompê-la [...] e fazer dela um mapa de exploração" (Nicolescu, 1999, p. 30).

As análises trazidas até aqui nos remetem a duas considerações fundamentais para respondermos às nossas perguntas. A CI é complexa, interdisciplinar e, portanto, aberta para investigar os supostos vazios que se estabelecem em suas fronteiras. Consequentemente, garante a indissociabilidade da relação sujeito/objeto, revelando, portanto, importantes atributos que a remetem à transdisciplinaridade.

Se considerarmos o rigor da Física com relação aos postulados Níveis de realidade e Lógica do Terceiro Incluído, conforme vimos em Nicolescu (1999), caberia perguntar também se a CI é capaz de se sustentar enquanto transdisciplinar?

Nos atendo inicialmente ao rigor preconizado por Nicolescu (1999), que coloca a Física como a única capaz de nos mostrar níveis de realidade nas correlações que se estabelecem entre os mundo micro e macrofísico, ousamos dizer que a CI pode, também, ocupar tal lugar. Isso porque tem em seu cerne, além da complexidade, pelo menos dois níveis de realidade oriundos das relações entre as linguagens humana e não humana (além do suporte), com possíveis desdobramentos ainda imprevisíveis.

A correlação entre os dois sistemas, ambos localizadas nas fronteiras do conhecimento da CI, reiteramos, pode nos remeter a pelo menos dois níveis de realidade. A comunicação não humana, possibilitada pela constituição das redes neurais e da inteligência, ambas artificiais, se dá por meio de um rigor matemático, que pode ser traduzido, grosso modo, no aperfeiçoamento de algoritmos que estabelecem as interconexões necessárias para que elas entrem em operação. Ainda assim, se mantém a dúvida se estaríamos diante de dois níveis de realidade oriundos de sistemas naturais, entre mundos macro e microfísicos, conforme preconiza Nicolescu (1999), quando se refere à Física.

Ora, se considerarmos a comunicação não humana decorrente de um processo matemático, portanto, humano, poder-se-ia classificá-la também como natural, ocorrendo, no entanto, em outro nível de realidade, por sua potencial capacidade de superar os princípios matemáticos dominados pelo ser humano, mesmo ainda não se tendo uma previsibilidade de suas consequências no mundo macrofísico. Discussões sobre a capacidade ou não de haver o controle humano sobre a inteligência de máquina, no campo ainda hipotético de uma superinteligência artificial, ganham corpo, especialmente no campo computacional.

Para Alfonseca et al. (2021, p. 76), não encontramos, hoje, garantia formal de uma segurança absoluta no momento em que "[...] executamos bilhões de programas de computador em máquinas conectadas globalmente", a ponto de não se poder provar "[...] que quando lançamos um aplicativo em nossos smartphones, não desencadearíamos uma reação em cadeia que leva à transmissão de códigos de lançamento de mísseis que iniciam uma guerra nuclear". Ao estudarem modelos de contenção para tal possibilidade, os autores admitem, porém, que os limites atuais dos cálculos impossibilitam um controle sobre a hipotética superinteligência.

O pressuposto, porém, precisa ser melhor investigado, como vem ocorrendo paulatinamente na CI, entre outras áreas do conhecimento. Em caso de sua validação, porém - aqui pegando emprestadas as palavras de Nicolescu (1999, p. 18-19), para descrever as consequências das correlações entre dois níveis de realidade -, podemos estar diante de uma ocorrência que "pode nos levar a repensar nossa vida individual e social, a fazer uma nova leitura dos conhecimentos antigos, a explorar de outro modo o conhecimento de nós mesmos, aqui e agora". A ideia de fazer o exercício hipotético se justifica para alargarmos as possibilidades, uma vez que, sob a perspectiva teórica de ultrapassar a relação cartesiana de realidade, de concepção de objeto, e, consequentemente, de lógica, podemos situar que a CI, desde a sua constituição, enquanto complexa, à revelia dos discursos epistêmicos, já transitava com tal potencial.

Resta-nos estabelecer as correlações da CI com o postulado da Lógica do Terceiro Incluído, preconizado por Nicolescu como também necessário para uma constituição possível da transdisciplinaridade. Nicolescu (1999, p. 24), partindo da física quântica, busca estabelecer um paralelo entre os axiomas do terceiro excluído da não-contradição, procurando mostrar que não existe contradição entre os dois axiomas. Segundo ele, isso ocorre se as concepções de verdadeiro e falso forem "[...] alargadas, de tal modo que as regras de implicação lógica digam respeito não mais a dois termos (A e não-A), mas a três termos (A, não-A e T), coexistindo no mesmo momento do tempo".

A condição T é que nos permitiria proceder a união dos contraditórios, de acordo com Nicolescu (1999, p. 130), a "[...] um nível diferente daquele em que A e não-A estão situados". Como adverte o próprio autor, precisamos estar atentos para não aceitarmos que a condição nos remeta à possibilidade de concebermos a transdisciplinaridade enquanto uma teoria completa, capaz de responder a questões do presente e do futuro, por nos apresentar a 
possibilidade de "[...] uma realidade multidimensional, estruturada em muitos níveis, substituindo a realidade do pensamento clássico de um único nível, unidimensional" (Nicolescu, 1999, p. 130).

Isso não ocorreria pelo fato de que, mesmo se o Terceiro Incluído possibilitasse processos de interações, seria necessário acontecer indefinidamente até se exaurir "[...] todos os níveis de realidade conhecidos ou concebíveis" (Nicolescu, 1999, p. 130). Por isso é que o autor sustenta a teoria, ao contrário de gerar a completude, como capaz de estimular "[...] uma condição aberta de conjunto de Níveis de Realidade" (Nicolescu, 1999, p. 130-131), impossibilitando, assim, que a constituição da transdisciplinaridade se encerre em si mesma.

Podemos perceber, no entanto, que a concepção da Física Quântica, referente às imbricações constitutivas para uma nova lógica que aceita, mas não encontra repouso na proposição binária, causa incômodo no mundo macrofísico. Como vimos no início deste artigo, tal preocupação esteve presente no universo de filósofos e cientistas que fizeram contraponto aos princípios cartesianos, contexto que concebeu, inclusive, os primeiros fundamentos da própria CI.

Isso implica dizer que a CI também traz consigo, desde seus fundamentos históricos, a possibilidade de coexistir entre a lógica binária e a lógica inclusiva, sendo, portanto, capaz de transitar em seus Níveis de Realidade a partir de tais possibilidades, dependendo do nível de complexidade em que estejam ocorrendo suas investigações. Assim, interpretamos que a CI pode se apoiar nessa tríade para desenvolver métodos transdisciplinares.

\section{CONCLUSÕES}

A dimensão transdisciplinar da CI, a partir da complexidade, dos níveis de realidade e do caráter polilógico implícitos em seu cerne, responde simultaneamente às três questões que motivaram este artigo. A CI, portanto, revela a sua vocação transdisciplinar por apresentar potenciais metodológicos de investigação capazes de sustentar estudos mais aprofundados sobre a própria dimensão humana, diante das transformações do mundo. Revelando-se transdisciplinar, o mapa metodológico da CI, a partir dos desdobramentos de sua própria evolução histórica, pode ser fundamental, por exemplo, na interpretação dos fenômenos advindos das disputas que sempre se estabeleceram entre as sociedades, em nível mundial, especialmente a partir da relação entre a consciência e a inteligência. Isso, porque a tecnologia se apresenta enquanto uma interface, que propicia tanto a ampliação do conhecimento quanto a dominação, instigando a CI a perceber tais fenômenos em seus diversos níveis e possibilidades lógicas que rompam, inclusive, tal dualismo.

Nesse sentido, em cenários de vocações neototalitárias que se revelam cada vez mais no presente, tendo a tecnologia como principal aliada para o estímulo de um consumo e desenvolvimento sem limites, assim como de construções de pós-verdades, a partir da negação da História, ou de sua reconstrução por meio de nossa capacidade crítica, concluímos também que o caráter transdisciplinar da CI pode contribuir para desnudar a tecnologia enquanto um epifenômeno que escamoteia as forças de dominação contidas em suas embalagens. Com isso, a condição de transdisciplina pode nos ajudar a perceber as nuances do desenvolvimento tecnológico que abarca os fenômenos da informação e da comunicação, especialmente enquanto um desdobramento da ação humana em sua jornada de sobrevivência na Terra.

A referida condição, por nos possibilitar a construção de mapas metodológicos abertos, sustentados na sua virtuosa incompletude epistemológica, permite à CI navegar nas fronteiras constituídas a partir da relação de ordem e desordem do próprio mundo, interpretando suas implicações nas disputas de ideais oriundos da diversidade que se estabelece na sociedade. A condição, como vimos ao longo do texto, está nos próprios desenvolvimentos epistemológicos da CI.

A implexidade de tais desdobramentos, inclusive, nos permite perceber o macrocosmo a partir do nosso microcosmo - e vice-versa -, demonstrando a potência da indissociabilidade entre sujeito e objeto, fazendo com que a condição transdisciplinar do ser humano mantenha aguçada a capacidade de interpretar a diversidade, em vários níveis da própria percepção. Trazer a Ciência para a condição humana, transdisciplinar, em especial a CI, por nos inspirar este trabalho, no entanto, não nos permite um empoderamento cego de busca a uma pretensa universalização do conhecimento, ou, até mesmo a justificativa da necessidade de uma democracia cognitiva enquanto verdades necessárias e absolutas, pois a tornaria também totalitária. Por isso, a necessidade de novas investigações que permitam, a partir de suas críticas e autocríticas, a sua constante renovação epistêmica, destacando que os autores aqui convidados para esta jornada foram fundamentais aos resultados de nossa indagação teórico-reflexiva. 


\section{REFERÊNCIAS}

Alfonseca, M., Cebrian, M., Anta, A. F., Coviello, L., Abeliuk, A., \& Rahwan, I. R. (2021). Superintelligence cannot be contained: lessons from computability theory. Journal of Artificial Intelligence Research(70), 65-76. doi: 10.1613/jair.1.12202

Araújo, C. A. Á. (2009). Correntes teóricas da ciência da informação. Ciência da informação, 38(3), 192-204. Recuperado de https://www.scielo.br/pdf/ci/v38n3/v38n3a13.pdf

Bachelard, G. (1978). O novo espírito científico. São Paulo: Abril Cultural.

Barreto, A. A. (2007). Uma história da ciência da informação. In Toutain, l. b. (eds). para entender a ciência da informação. DUFBA: Salvador.

Bolshaw, M. (2015). Breve história da epistemologia. Revista Temática, 11(12), 16-25. Recuperado de https://periodicos .ufpb.br/index.php/tematica/article/view/27010

Borko, H. (1968). Information science: what is it? American Documentation, 19(1), 3-5.

Bush, V. (1945). As we may think. The Atlantic, 7.

Capurro, R. (2003). Epistemologia e ciência da informação. In $V$ encontro nacional de pesquisa em ciência da informação (enancib). Belo Horizonte, MG.

Cornelius, I. (1996). Meaning and method in information studies. New Jersey: Ablex.

Cunha, K. M. R. d. (2009). Jornalismo e a realidade de segunda ordem: subjetividade à luz de heinz von foerste. In Xxxii congresso brasileiro de ciências da comunicação. Curitiba.

Kant, I. (1979). Crítica da razão pura. São Paulo: Abril Cultural.

Leibiniz, G. W. (1979). A monadologia: discursos de metafísica e outros textos. São Paulo: Abril Cultural.

Marteleto, R., \& Saldanha, G. (2016). Informação: qual estatuto epistemológico. In Morigi, v. and jacks, n. and golin, c. (eds.). epistemologias, comunicação e informação. Sulina: Porto Alegre.

Morin, E. (1996). Ciência com consciência. Rio de Janeiro: Bertrand Brasil.

Morin, E. (2001). Os desafios da complexidade. In $A$ religação dos saberes: o desafio do século xxi. Bertrand Brasil: Rio de Janeiro.

Morin, E. (2003). Os sete saberes necessários à educação do futuro. São Paulo: Cortez.

Morin, E. (2011). O método 4: as ideias - habitat, vida, costumes, organização. Porto Alegre: Sulina.

Nicolescu, B. (1999). Um novo tipo de conhecimento: transdisciplinaridade. In I encontro catalisador do cetrans, escola do futuro (p. 1-10). Itatiba, SP.

Pinheiro, L. V. R. (2013). Fronteiras e horizontes da pesquisa em ciência da informação no brasil. In Albagli, s. (eds.). fronteiras da ciência da informação. IBICT: Brasília.

Pombo, O. (2004). Epistemologia da interdisciplinaridade. In Colóquio interdisciplinaridade, humanismo e universidade (p. 1-29). Porto, Portugal.

Santos, N. B. d. (2003). O paradigma holográfico e a utopia de vannevar bush. In $V$ encontro nacional de pesquisa em ciência da informação (enancib). Belo Horizonte, MG.
Saracevic, T. (1996). Ciência da informação: origem, evolução e relações. Perspectivas em Ciência da Informação, 1(1), 41-62. Recuperado de http://portaldeperiodicos.eci .ufmg.br/index.php/pci/article/view/235/22

Silva, J. L. C. (2016). Trajetórias e contribuições de harold borko para a ciência da informação no âmbito do artigo "informatio science: what is it? Conhecimento em Ação, 1(1), 29-46. doi: 10.47681/rca.v1i1.3393

Vico, G. (1979). Princípios de (uma) ciência nova (acerca da natureza comum das nações). São Paulo: Abril Cultural.

Weaver, W. (1948). Science and complexity. American Scientist, 36(4), 536-544.
Como citar este artigo (APA):

Daher Junior, F. J. \& Borges, J. (2021). Ciência da Informação: uma utopia transdisciplinar?. AtoZ: novas práticas em informação e conhecimento, 10(2), 89 - 96. Recuperado de: http://dx.doi.org/10.5380/atoz.v10i2 .79257 